\title{
Contribution of specialists to antenatal care in France: impact on level of care during pregnancy and delivery
}

\author{
BRUNO HUBERT, BEATRICE BLONDEL, AND MONIQUE KAMINSKI \\ From the Unité de Recherches Epidémiologiques sur la Mère et l'Enfant, INSERM, 16 Avenue Paul \\ Vaillant-Couturier, 94807 Villejuif Cédex, France
}

SUMMARY This study was based on a survey of a national sample of births in France in 1981 which included 5508 women. Four pathways of antenatal care were defined according to the stage of pregnancy at first intervention of a specialist, as opposed to a general practitioner, in the care of the pregnancy. Taking into account the sociodemographic and medical characteristics of the women in a logistic regression, a large number of antenatal visits, an ultrasound examination, and hospitalisation during pregnancy were more frequent when the degree of specialisation of the pathway increased. But the influence of pathways was less significant for deliveries. Caesarean section rates, for example, did not vary according to pathway. However, induction of labour and intrapartum electronic fetal monitoring were less frequent among women cared for solely by a general practitioner than among those who had consulted a specialist at least once during pregnancy. The increase in medical care and the role of the specialist in antenatal care are discussed.

In several European countries, such as Belgium, West Germany, and France, pregnant women may choose the place where they will get their antenatal care and the person who will be responsible for it. ${ }^{1}$ In France in $1981,38 \%$ of pregnant women were cared for exclusively by a specialist, $9 \%$ exclusively by a general practitioner, while, for $53 \%$, antenatal care was shared between both of them. ${ }^{2}$ The consequences of these patterns of care have been studied in several countries. In Belgium, it has been shown that the frequency of visits differed between the public and private sectors; ${ }^{3}$ in France, the degree to which care was ensured by specialists constituted one of the main sources of inequality. ${ }^{4}$ Since these studies were limited to the antenatal period and, specifically, to the number of visits, the impact of this specialisation on other aspects of care during pregnancy or on the conditions of delivery remains unknown.

Other factors have an influence on antenatal care: women under 20 years of age, women with a high parity, a low educational level or a residence in a rural area make fewer visits and are less frequently seen by a specialist. ${ }^{5.7}$ But few studies have simultaneously taken into account all these maternal characteristics in order to evaluate the role of the type of care providers on the level of care. The objective of this study has been to specify the role of the degree of specialisation in antenatal care, while taking into account maternal characteristics and complications during pregnancy.
We have tried to determine whether the qualification of the person responsible for care was associated with the level of antenatal care and whether these differences in antenatal care also had an influence on conditions of delivery. We used the "pathway" to express the process by which pregnant women go through the various systems of antenatal care existing in France.

\section{Population and methods}

The data were derived from a national survey carried out in France in $1981 .^{2}$ This study included a representative sample of 5508 births. Collection of the data was made: (1) by interview of the mothers, after delivery, about their sociodemographic situation, antenatal care, pregnancy complications, and outcome of previous pregnancies; and (2) by abstraction of information on the delivery and neonatal period from hospital records.

The definition of the pathways was based on the trimester of pregnancy during which a specialist first undertook the antenatal care. The concept of specialist included the following qualifications: gynaecologist, obstetrician, midwife, and doctor in training to become a gynaeco-obstetrician. Use of this definition meant the exclusion of 588 women $(11 \%$ of the sample) based on the following reasons: lack of information on the person responsible for the 
antenatal care for at least one trimester $(6 \%)$; absence of visit for at least one trimester $(3 \%)$; isolated intervention of a specialist, that is, with no continuity during the following trimester or trimesters $(2 \%)$. After these exclusions, the analysis was carried through on 4920 women.

Four pathways were defined:

pathway 1: care provided exclusively by a general practitioner ( $8 \%$ of the women);

pathway 2: care by a specialist beginning in the third trimester (17\% of the women);

pathway 3: care by a specialist beginning in the second trimester (16\% of the women);

pathway 4: care by a specialist beginning in the first trimester ( $59 \%$ of the women).

Three variables were used to characterise care during pregnancy: more than seven visits, at least one ultrasound examination, and hospitalisation. Indicators of care during labour and delivery were caesarean section, induction of labour with oxytocin or prostaglandins, and intrapartum electronic fetal monitoring.

Maternal sociodemographic and medical characteristics were taken into consideration: (1) parity; (2) age; (3) sociocultural level, measured by diploma (no diploma, intermediate level diploma corresponding to 7 to 10 years of schooling, and upper level diploma based on at least 12 years of schooling); (4) rural or urban residence, rural environment being defined as towns having less than 4000 inhabitants and located away from an urban centre; (5) history of adverse outcome in the previous pregnancy: perinatal death, preterm delivery (before 37 completed weeks of gestation), birthweight less than $2500 \mathrm{~g}$, malformation, spontaneous abortion, or ectopic pregnancy.

In the analysis of antenatal care, the occurrence of at least one of the following complications was taken into account: hypertension (systolic blood pressure $>13$ or diastolic $>8)$, proteinuria $(>0.1 \mathrm{~g} / \mathrm{l})$, bleeding, threatened abortion or preterm delivery. In addition, the trimester of occurrence of these complications was considered in the study of the number of antenatal visits.

For the study of induction, we took into account post term deliveries (pregnancy duration of more than 42 weeks).

For intrapartum electronic fetal monitoring, we noted the presence of at least one of the principal indications for this examination proposed by Niswander et al: ${ }^{8}$ severe hypertension (which we judged in our data to be present when there was a prescription of an antihypertensive during pregnancy), diabetes mellitus, suspected intrauterine growth retardation, gestational age less than 37 or more than 42 weeks, meconium-stained amniotic fluid or induction by oxytocin or prostaglandins.

In order to study the relation between antenatal care pathways and delivery conditions, the maternity units were classified in three groups according to their annual number of deliveries: less than 500, 500 to 1199 and 1200 deliveries or more yearly. This criterion is an indicator of the level of equipment available and the rate of obstetric interventions practised in the units. ${ }^{9}$

We first compared the characteristics of the women in each antenatal care pathway. Then to study the care during pregnancy and delivery we used the following procedure: we first examined the relation between care indicators and both pathways and characteristics of the women; secondly, we studied the specific effect of the pathways on care in a multivariate analysis, taking into account all the maternal characteristics for which a significant relation to care has been observed in the previous stage of analysis. Age and parity do not appear in the tables, but they were included in the models whenever they were significantly related to care in the univariate analysis.

Statistical methods used were Pearson's $\chi^{2}$ test and multiple logistic regression; statistical significance of the adjusted odds ratios was tested by the maximum likelihood ratio. 1011

\section{Results}

Characteristics of the women differed according to pathway (table 1); in the pathways where visits from specialists began early, women were more frequently of low parity, older age, high educational level, urban place of residence, with an adverse outcome of the previous pregnancy, or early occurrence of a complication during the index pregnancy.

\section{ANTENATAL CARE}

The proportion of women having had more than seven antenatal visits increased with the earliness of a specialist's involvement in care (table 2). The frequency of visits increased with educational level, residence in an urban environment, presence of adverse outcome of the previous pregnancy, and early occurrence of complication. After adjustment for maternal characteristics in logistic regression, the pathways continued to have an important effect on care, while these characteristics all maintained their specific effect on the frequency of visits.

Ultrasound examination during pregnancy was strongly linked to the degree of specialisation of the pathway: the frequency was only $51 \%$ in pathway 1 but increased regularly in the intermediate pathways to reach $90 \%$ in pathway 4 (table 3). But maternal characteristics also played an important role, identical overall to that found for the number of visits. After adjustment, having an ultrasound examination 
Table 1 Maternal characteristics according to antenatal care pathways

\begin{tabular}{|c|c|c|c|c|c|}
\hline & $\begin{array}{c}\text { Pathway I } \\
\% \\
\text { (No) }\end{array}$ & $\begin{array}{c}\text { Pathway } 2 \\
\% \\
\text { (No) }\end{array}$ & $\begin{array}{c}\text { Pathway } 3 \\
\% \\
\text { (No) }\end{array}$ & $\begin{array}{c}\text { Pathway } 4 \\
\% \\
\text { (No) }\end{array}$ & \\
\hline $\begin{array}{l}\text { Parity } \\
0 \\
1-2 \\
3 \text { or more }\end{array}$ & $\begin{array}{r}37 \\
48 \\
15 \\
(411)\end{array}$ & $\begin{array}{r}41 \\
47 \\
12 \\
(828)\end{array}$ & $\begin{array}{r}43 \\
51 \\
6 \\
(790)\end{array}$ & $\begin{array}{r}41 \\
52 \\
7 \\
(2877)\end{array}$ & $* * *$ \\
\hline $\begin{array}{l}\text { Age }(y r) \\
\text { less than } 20 \\
20 \text { to } 34 \\
34+\end{array}$ & $\begin{array}{r}9 \\
86 \\
5 \\
(410)\end{array}$ & $\begin{array}{r}9 \\
86 \\
5 \\
(830)\end{array}$ & $\begin{array}{r}7 \\
89 \\
4 \\
(792)\end{array}$ & $\begin{array}{r}3 \\
90 \\
7 \\
(2859)\end{array}$ & $* * *$ \\
\hline $\begin{array}{l}\text { Diploma } \\
\text { None } \\
\text { Intermediate } \\
\text { Upper }\end{array}$ & $\begin{array}{r}33 \\
57 \\
10 \\
(384)\end{array}$ & $\begin{array}{r}32 \\
56 \\
12 \\
(786)\end{array}$ & $\begin{array}{r}23 \\
58 \\
19 \\
(747)\end{array}$ & $\begin{array}{r}17 \\
61 \\
32 \\
(2712)\end{array}$ & $* * *$ \\
\hline Rural environment & $\begin{array}{r}48 \\
(405)\end{array}$ & $\begin{array}{r}46 \\
(821)\end{array}$ & $\begin{array}{r}35 \\
(785)\end{array}$ & $\begin{array}{r}24 \\
(2831)\end{array}$ & $* * *$ \\
\hline $\begin{array}{l}\text { Adverse outcome of } \\
\text { previous pregnancy }\end{array}$ & $\begin{array}{r}10 \\
(379)\end{array}$ & $\begin{array}{r}10 \\
(787)\end{array}$ & $\begin{array}{r}12 \\
(753)\end{array}$ & $\begin{array}{r}17 \\
(2732)\end{array}$ & $* * *$ \\
\hline $\begin{array}{l}\text { Trimester of pregnan } \\
\text { None } \\
\text { 3rd } \\
\text { 2nd } \\
\text { 1st }\end{array}$ & $\begin{array}{r}73 \\
14 \\
5 \\
9 \\
(390)\end{array}$ & $\begin{array}{r}69 \\
17 \\
5 \\
9 \\
(808)\end{array}$ & $\begin{array}{r}67 \\
15 \\
10 \\
8 \\
(774)\end{array}$ & $\begin{array}{r}64 \\
15 \\
8 \\
12 \\
(2803)\end{array}$ & $* * *$ \\
\hline
\end{tabular}

Table 2 Percentage of pregnant women with more than seven antenatal visits according to antenatal care pathways and maternal characteristics

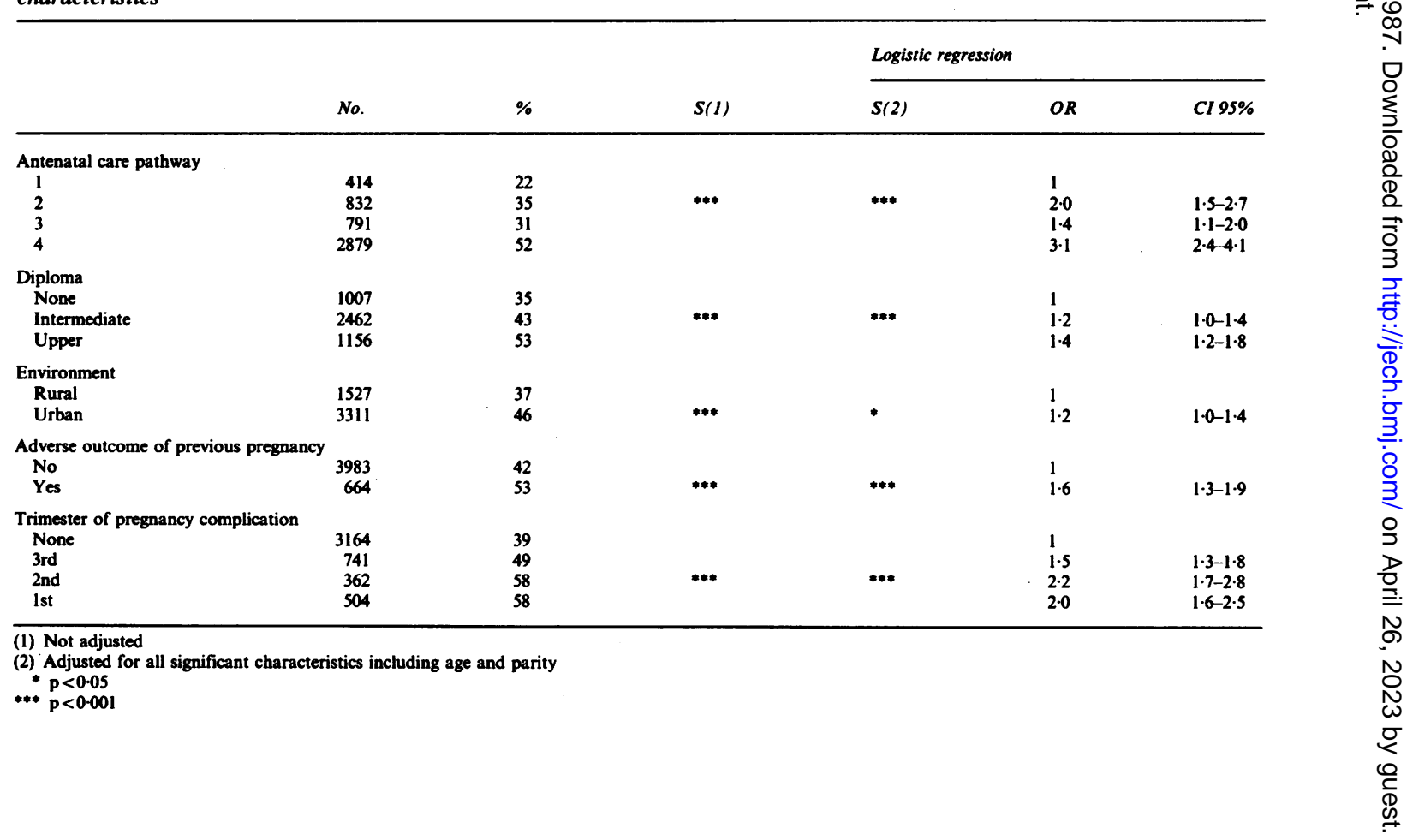


Table 3 Frequency of ultrasound examination according to antenatal care pathway and maternal characteristics

\begin{tabular}{|c|c|c|c|c|c|c|}
\hline & \multirow[b]{2}{*}{ No. } & \multirow[b]{2}{*}{$\%$} & \multirow[b]{2}{*}{$s(1)$} & \multicolumn{3}{|c|}{ Logistic regression } \\
\hline & & & & $S(2)$ & $O R$ & Cl $95 \%$ \\
\hline \multicolumn{7}{|c|}{ Antenatal care pathway } \\
\hline 1 & 392 & 51 & & & 1 & \\
\hline 2 & 813 & 72 & $* * *$ & **** & $2 \cdot 4$ & $1 \cdot 8-3 \cdot 2$ \\
\hline 3 & 774 & 83 & & & 3.6 & $2.7-4.9$ \\
\hline 4 & 2829 & 90 & & & 6.6 & $5 \cdot 1-8 \cdot 7$ \\
\hline \multicolumn{7}{|l|}{ Diploma } \\
\hline None & 986 & 72 & & & 1 & \\
\hline Intermediate & 2416 & 84 & *** & **** & 1.7 & $1 \cdot 2-2 \cdot 4$ \\
\hline Upper & 1138 & 91 & & & $2 \cdot 4$ & $1.4-4.0$ \\
\hline \multicolumn{7}{|l|}{ Environment } \\
\hline Rural & 1490 & 77 & & & 1 & \\
\hline Urban & 3245 & 85 & $* * *$ & NS & $1 \cdot 2$ & $1 \cdot 0-1 \cdot 4$ \\
\hline \multicolumn{7}{|c|}{ Adverse outcome of previous pregnancy } \\
\hline No & 3912 & 82 & & & 1 & \\
\hline Yes & 650 & 89 & $* * *$ & $* * *$ & 1.7 & $1 \cdot 3-2 \cdot 2$ \\
\hline \multicolumn{7}{|c|}{ Pregnancy complication } \\
\hline No & 3095 & 80 & & & 1 & \\
\hline Yes & 1591 & 88 & $* * *$ & $* * *$ & 1.7 & $1 \cdot 4-2 \cdot 1$ \\
\hline
\end{tabular}

Table 4 Frequency of hospitalisation during pregnancy according to antenatal care pathway and maternal characteristics

\begin{tabular}{|c|c|c|c|c|c|c|}
\hline & \multirow[b]{2}{*}{ No. } & \multirow[b]{2}{*}{$\%$} & \multirow[b]{2}{*}{$s(1)$} & \multicolumn{3}{|c|}{ Logistic regression } \\
\hline & & & & $S(2)$ & $O R$ & CI $95 \%$ \\
\hline \multicolumn{7}{|c|}{ Antenatal care pathway } \\
\hline 1 & 410 & 7 & & & 1 & \\
\hline 2 & 826 & 11 & **** & *** & 1.8 & $1 \cdot 1-3 \cdot 0$ \\
\hline 3 & 788 & 15 & & & 2.5 & $1.5-4 \cdot 1$ \\
\hline 4 & 2866 & 18 & & & 2.8 & $1.8-4.5$ \\
\hline \multicolumn{7}{|l|}{ Diploma } \\
\hline None & 1000 & 18 & & & 1 & \\
\hline Intermediate & 2461 & 14 & * & * & 0.7 & $0.6-0.9$ \\
\hline Upper & 1153 & 16 & & & 0.7 & $0 \cdot 6-1 \cdot 0$ \\
\hline \multicolumn{7}{|l|}{ Environment } \\
\hline Rural & 1519 & 13 & & & 1 & \\
\hline Urban & 3303 & 17 & $* * *$ & NS & $1 \cdot 2$ & $1.0-1.5$ \\
\hline \multicolumn{7}{|c|}{ Adverse outcome of previous pregnancy } \\
\hline No & 3974 & 14 & & & 1 & \\
\hline Yes & 663 & 26 & $* * *$ & $* * *$ & 1.7 & $1 \cdot 4-2 \cdot 2$ \\
\hline \multicolumn{7}{|c|}{ Pregnancy complication } \\
\hline No & 3164 & 6 & & & 1 & \\
\hline Yes & 1606 & 33 & $* * *$ & *** & 7.4 & $6 \cdot 1-9 \cdot 0$ \\
\hline
\end{tabular}

(1) Not adjusted

(2) Adjusted for all significant characteristics including age and parity

$\mathrm{p}<0.05$

$* * * \begin{aligned} & p<0.05 \\ & p<0.001\end{aligned}$

remained significantly linked to the pathway; all maternal characteristics, except place of residence, remained significant.

The hospitalisation rate increased with the degree of specialisation of the care pathway (table 4). Hospitalisation was more frequent among women who lived in an urban environment, who had a history of adverse outcome of the last previous pregnancy, or who had a complication of the pregnancy; it was less frequent among women with a high educational level. After adjustment, only the relation between hospitalisation and place of residence disappeared. 
Table 5 Place of delivery according to antenatal care pathway

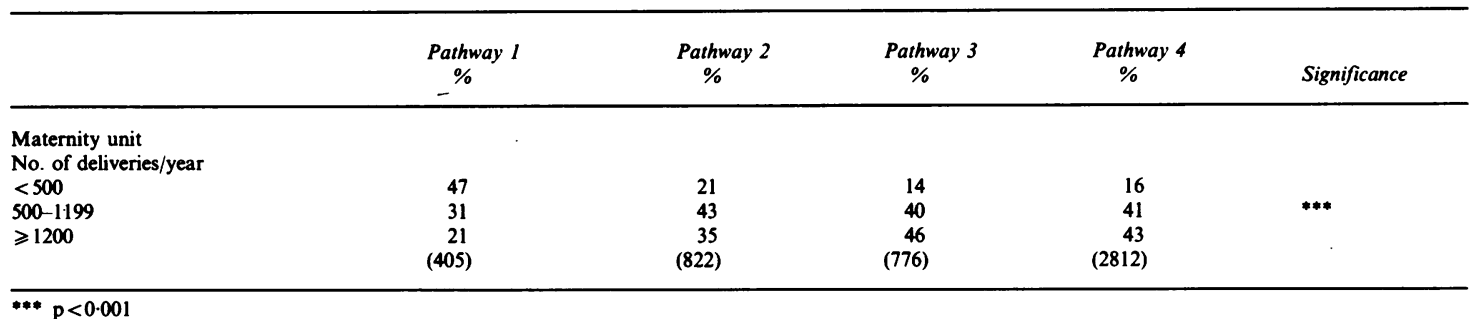

Table 6 Frequency of induction of labour according to antenatal care pathway, place of delivery, and maternal characteristics

\begin{tabular}{|c|c|c|c|c|c|c|}
\hline & \multirow[b]{2}{*}{ No. } & \multirow[b]{2}{*}{$\%$} & \multirow[b]{2}{*}{$S(1)$} & \multicolumn{3}{|c|}{ Logistic regression } \\
\hline & & & & $S(2)$ & $O R$ & CI $95 \%$ \\
\hline \multicolumn{7}{|c|}{ Antenatal care pathway } \\
\hline 1 & 412 & 3 & & & 1 & \\
\hline 2 & 832 & 8 & $* * *$ & $* *$ & $2 \cdot 4$ & $1 \cdot 2-4.9$ \\
\hline 3 & 791 & 10 & & & 2.9 & $1 \cdot 4-5 \cdot 7$ \\
\hline 4 & 2882 & 9 & & & $2 \cdot 9$ & $1 \cdot 5-5 \cdot 5$ \\
\hline \multirow{2}{*}{\multicolumn{7}{|c|}{$\begin{array}{l}\text { Maternity unit } \\
\text { No. of deliveries/year }\end{array}$}} \\
\hline & & & & & & \\
\hline$<500$ & 923 & 6 & & & 1 & \\
\hline $500-1199$ & 1944 & 9 & $*$ & NS & $1 \cdot 2$ & $0.9-1 \cdot 7$ \\
\hline$\geqslant 1200$ & 1945 & 10 & & & $1 \cdot 3$ & $1 \cdot 0-1 \cdot 9$ \\
\hline \multicolumn{7}{|l|}{ Diploma } \\
\hline None & 996 & 6 & & & 1 & \\
\hline \multicolumn{7}{|l|}{ Environment } \\
\hline Rural & 1503 & 8 & & & & \\
\hline Urban & 3280 & 9 & NS & & & \\
\hline \multicolumn{7}{|c|}{ Adverse outcome of previous pregnancy } \\
\hline No & 3269 & 9 & & & & \\
\hline Yes & 653 & 10 & NS & & & \\
\hline \multicolumn{7}{|c|}{ Gestational age $>42$ weeks } \\
\hline No & 4414 & 9 & & & 1 & \\
\hline Yes & 158 & 17 & $* * *$ & $* * *$ & $2 \cdot 2$ & $1.4-3.5$ \\
\hline
\end{tabular}

\section{DELIVERY CONDITIONS}

At delivery, the women in the four pathways were distributed differently among the three types of maternity units defined according to the annual number of deliveries (table 5). The women cared for exclusively by a general practitioner gave birth more frequently in small units.

The caesarean section rate did not differ significantly among the four pathways: $9 \%, 10 \%$, $11 \%$, and $11 \%$ respectively, for pathways $1,2,3$, and 4 .

Induction of labour was less often performed among women of pathway 1 (table 6). The rate of inductions was greater among the women with a high level of education and among those with a prolonged pregnancy. After adjustment in a model including the type of maternity unit, the educational level, and the duration of gestation, induction of labour was almost three times less frequent in pathway 1 than in the others, which did not otherwise differ among themselves. The type of maternity unit appeared to be of no significance; on the other hand, level of education and length of gestation retained special importance. Intrapartum electronic fetal monitoring (EFM) was also less frequent among those in pathway 1 (table 7). The role of medical indications of EFM was very weak: only $77 \%$ of the women with such indicators were monitored with EFM versus $67 \%$ of the other women. After taking into account the type of maternity unit, parity, age, place of residence, and 
Table 7 Frequency of intrapartum electronic fetal monitoring according to antenatal care pathway, place of delivery, and maternal characteristics

\begin{tabular}{|c|c|c|c|c|c|c|}
\hline & \multirow[b]{2}{*}{ No. } & \multirow[b]{2}{*}{$\%$} & \multirow[b]{2}{*}{$S(1)$} & \multicolumn{3}{|c|}{ Logistic regression } \\
\hline & & & & $S(2)$ & $O R$ & CI $95 \%$ \\
\hline \multicolumn{7}{|c|}{ Antenatal care pathway } \\
\hline 1 & 409 & 55 & & & 1 & \\
\hline 2 & 823 & 69 & $* * *$ & $* * *$ & $1 \cdot 6$ & $1 \cdot 2-2 \cdot 1$ \\
\hline 4 & 2852 & 71 & & & $1 \cdot 6$ & $1 \cdot 3-2 \cdot 1$ \\
\hline \multicolumn{7}{|c|}{$\begin{array}{l}\text { Maternity unit } \\
\text { No. of deliveries/year }\end{array}$} \\
\hline$<500$ & 913 & 59 & & & 1 & \\
\hline $500-1199$ & 1922 & 66 & $* * *$ & $* * *$ & $1 \cdot 2$ & $1 \cdot 0-1 \cdot 4$ \\
\hline$\geqslant 1200$ & 1929 & 77 & & & $2 \cdot 0$ & $1 \cdot 6-2 \cdot 4$ \\
\hline \multicolumn{7}{|l|}{ Diplomas } \\
\hline None & 987 & 69 & & & & \\
\hline Upper & 1133 & 71 & & & & \\
\hline \multicolumn{7}{|l|}{ Environment } \\
\hline Rural & 1486 & 66 & & & 1 & \\
\hline Urban & 3250 & 71 & $* * *$ & NS & $1 \cdot 1$ & $0 \cdot 9-1 \cdot 3$ \\
\hline \multicolumn{7}{|c|}{ Adverse outcome of previous pregnancy } \\
\hline No & 3909 & 70 & & & & \\
\hline Yes & 645 & 70 & NS & & & \\
\hline \multicolumn{7}{|c|}{ Medical indication for monitoring } \\
\hline No & 3269 & 67 & & & 1 & \\
\hline Yes & 1200 & 77 & $* * *$ & $* * *$ & 1.6 & $1.4-1.9$ \\
\hline
\end{tabular}

medical indications, EFM remained less frequent among the women of pathway 1 . In this model, place of residence was no longer significant, contrary to what one observed for medical indications and the type of maternity unit.

\section{Discussion}

This study stressed the important influence on antenatal care of the degree of specialisation of the pathway: the amount of care increased with the earliness of the specialist's intervention. During delivery, the influence of pathways was less important. Women in the most specialised pathways gave birth more frequently in large maternity units. However, the rate of obstetric interventions was overall the same in the various pathways, except among the women cared for exclusively by a general practitioner.

\section{DEFINITIONS OF PATHWAYS}

In this study, the earliness of the specialist's involvement in antenatal care has been used rather than the proportion of antenatal visits by a specialist. This definition made it possible to take into account the trimester in which a complication appeared in the course of a pregnancy, and to specify the "dose- response" effect between the pathway's degree of specialisation and the amount of antenatal care. It also allowed one to know the qualification of the person responsible for care during the last trimester, who can have an influence on the management of labour and delivery. This definition also reflected a mechanism common in France - transfer of care from general practitioner to specialist in the second or third trimester of pregnancy-which accounted for the small proportion $(2 \%)$ of women excluded from the study because they had only an isolated visit from a specialist.

There were several reasons for including midwives with the specialists: midwives have a three-year training in obstetrics. When they are involved in antenatal care, they generally work within a maternity unit, along with specialists, and are seldom solely responsible for the supervision of a pregnancy. In our study population, only 46 women were cared for exclusively by a midwife.

\section{ACCESSIBILITY OF CARE}

In France in 1981, as already observed earlier, ${ }^{6}$ the choice of specialised antenatal care was largely determined by the sociodemographic characteristics of the women. But, apart from the influence of the 
specialisation of the medical pathways, important disparities in care have persisted; they are linked to differences of geographic and sociocultural accessibility. ${ }^{12}$ Geographic accessibility, estimated from the place of residence, had an influence on antenatal care, but this influence was attenuated after adjustment for the other sociodemographic variables and the pathways. This appears to indicate that the differences perceived are to a large extent influenced by the supply of services.

After medical complications and care pathways had been taken into account, women with a high educational level tended to have more examinations and interventions. The importance of educational level was also reported in a study on the diffusion of ultrasound examinations in France between 1976 and $1981 .{ }^{12}$ These results suggest that care was not given strictly for medical reasons and that the requests of women or their social situation influenced medical behaviour. ${ }^{13}$ On the other hand, hospitalisation during pregnancy was more frequent among women with a low educational level. This finding agreed with that of Mizrahi and Mizrahi ${ }^{14}$ who observed that "an important substitution takes place between outpatient visits and hospitalisation as income increases".

\section{MEDICAL PRACTICES}

The "dose-response" relationship between the degree of specialisation and the number of visits and ultrasound examinations reflected a difference in practices between general practitioners and specialists. By training, specialists have an approach to pregnancy focused on diseases and they tend to have frequent recourse to visits and procedures, while general practitioners tend to be more orientated to supervision and advice adapted to a normal pregnancy ${ }^{15}$ and, by the same token, are less interventionist. Their work organisation is also different: specialists are accustomed to regular and planned appointments while general practitioners exercise a form of care that is first of all adapted to the four visits recommended by the Ministry of Health. Concerning interventions during labour and delivery, differences depended upon whether or not a specialist was providing the care in the third trimester. That the smallest number of obstetric interventions occurred in pathway 1 can also be explained by the fact that, in this pathway, deliveries often took place in very small maternity units (fewer than 300 deliveries annually) or were carried out by a general practitioner. ${ }^{9}$

\section{MODIFICATIONS IN THE PROVISION OF} OBSTETRIC CARE

The results of this study must be examined in the context of the modifications in care during pregnancy and delivery in France. Specialisation of antenatal care increased from 1976 to 1981; the proportion of general practitioners providing complete care to pregnant women declined from $20 \cdot 8 \%$ to $8.8 \%$. $^{2}$ The number of gynaecologists and obstetricians in France increased from 3158 in 1980 to 3994 in 1984, bringing the rate of these specialists up from 3.9 to 5.3 per 1000 births-an increase of $36 \%$ in four years. ${ }^{16}$

In the same way, the number of procedures and interventions increased between 1976 and 1981: the proportion of women having had more than seven visits rose from 25 to $42 \%$, ultrasound examinations from 11 to $82 \%$, hospitalisation during pregnancy from 13 to $16 \%$, intrapartum electronic fetal monitoring from 31 to $71 \%$, induction of labour from 7 to $8 \%$, and caesarean sections from 8.5 to $11 \%{ }^{2}$ These augmentations concerned to a great extent screening in pregnancy; interventions increased more moderately and did not attain the rates found in other countries such as the United States where, during the same period, caesarean section rates increased from 10.4 to $17.9 \%$. ${ }^{17}$

Two factors have contributed to this increase in medical care: (1) the specific effect of procedures and interventions: this is the case, for example, of intrapartum electronic fetal monitoring associated with an increased risk of caesarean section ${ }^{18}{ }^{19}$; (2) the specific effect of specialists who play a dual function in the increase of care: by their leading role in the use of new technologies and by their increasing involvement in the supervision of normal pregnancies. This phenomenon leads to a rapid and large-scale use of recent technological innovations for pregnant women, whether their pregnancy is complicated or not. However, the effectiveness of these practices has not always been sufficiently assessed, and many uncertainties remain as to what constitutes optimum care for a normal pregnancy. ${ }^{20-25}$

THE ROLES OF GENERAL PRACTITIONER, MIDWIFE, AND SPECIALIST

The above observations lead one to reflect on the respective roles of general practitioner, midwife, and specialist in antenatal care. Keirse, Parboosingh, and Robinson have shown how these three health professions complement each other. ${ }^{152627}$ Specialists are trained to care for obstetric disorders; general practitioners integrate antenatal care in an overall supervision of the health of women and children and are in a better position to ensure routine care; midwives have a privileged role in assuring primary care and offering pregnant women support and advice adapted to their situation. This practice is well perceived in the countries of northern Europe where obstetricians take charge of complicated pregnancies or assure a limited number of antenatal visits for normal pregnancies. ${ }^{1}$ The same type of organisation is 
at the base of experience in Aberdeen: here, through a better definition of the objectives of antenatal care, it has been possible to achieve, among other things, a more balanced share of antenatal care visits between specialists and general practitioners for normal pregnancies. ${ }^{28}$ Such an approach may be more difficult to pursue in systems of care that are more competitive in nature, such as the one in France.

\section{Conclusion}

Our study has illustrated the relation between the specialisation of antenatal care and the amount of care and number of interventions. The question remains whether increased specialisation is desirable for those women experiencing a normal pregnancy, as this specialisation favours the diffusion of procedures and techniques, the effectiveness of which has not been sufficiently evaluated.

Correspondence should be addressed to: Béatrice Blondel, U 149 INSERM, 16, Avenue Paul VaillantCouturier, 94807 Villejuif cédex, France.

\section{References}

${ }^{1}$ Blondel B, Pusch D, Schmidt E. Some characteristics of antenatal care in 13 European countries. $\mathrm{Br} J$ Obstet Gynaecology 1985; 92: 565-8.

${ }^{2}$ Rumeau-Rouquette C, du Mazaubrun C, Rabarison Y (eds). Naitre en France. 10 ans d'évolution 1972-1981. Paris: INSERM-Doin 1984.

${ }^{3}$ Wollast E, Vandenbussche P, Buekens P. Evaluation de la surveillance prénatale en Belgique et comparaison entre les secteurs médicaux publiques et privés. Rev Epidém et Santé Publ 1986; 34: 52-8.

${ }^{4}$ Blondel B, Kaminski M, du Mazaubrun C, RumeauRouquette C. Surveillance prénatale et filiéres médicales pendant la grossesse. Rev Epidém et Santé Publ 1982; 30: 21-34.

${ }^{5}$ Robine JM, Maquin P, Nicaud V, Hatton F. Facteurs déterminants des pratiques de santé: exemple de la surveillance de la grossesse en milieu rural et urbain. $R e v$ Epidém et Santé Publ 1985; 33: 203-11.

${ }^{6}$ Blondel B, Kaminski M, Bréart G. Antenatal care and maternal demographic and social characteristics. Evolution in France between 1972 and 1976. J Epidemiol Community Health 1980; 34: 157-63.

${ }^{7}$ Cooney JP. What determines the start of prenatal care? Prenatal care, insurance and education. Med Care 1985; 23: 986-97.

${ }^{8}$ Niswander K, Henson G, Elbourne D, et al. Adverse outcome of pregnancy and the quality of obstetric care. Lancet 1984; ii: 827-31.
${ }^{9}$ Hubert B. Spécialisation de la surveillance prénatale: effets sur les soins pendant la grossesse et sur les conditions de l'accouchement. Paris: Memoire de DEA, 1986.

10 Dixon DJ, et al. BMDP statistical software. Berkeley: University of California Press, 1985.

${ }^{11}$ Kleinbaum DG, Kupper LL, Morganstern $\mathbf{H}$. Epidemiologic research. Belmont: Lifetime Learning Publication, 1982.

12 Poisson-Salomon AS, Bréart G, Maillard F, RumeauRouquette C. Diffusion of ultrasound examination during pregnancy in France between 1976 and 1981. Int $J$ Epidemiol 1987; 16: 234-8.

${ }^{13}$ Garcia J, Blondel B, Saurel-Cubizolles MJ. The social needs of childbearing families. Social policies and the organisation of health care. In: Effective care in pregnancy and childbirth. Enkin M, Keirse M, Chalmers I (eds). Oxford: Oxford University Press, in press.

${ }^{14}$ Mizrahi A, Mizrahi A. Influence des facteurs socioéconomiques sur l'hospitalisation. Paris: CREDOC, 1977.

${ }^{15}$ Keirse MJ. Interaction between primary and secondary antenatal care, with particular reference to the Netherlands. In: Effectiveness and satisfaction in antenatal care. Enkin M, Chalmers I (eds). London: SIMP/ Heinemann, 1982; 222-33.

${ }^{16}$ Caisse Nationale d'Assurance Maladie. Carnets statistiques, 1985; 20.

${ }^{17}$ Placek PJ, Taffel S, Moien M. Cesarean section delivery rates: United States, 1981. Am J Public Health 1983; 73: 861-2.

${ }^{18}$ Leveno KJ, Cunningham FG, Nelson N, et al. A prospective comparison of selective and universal electronic fetal monitoring in 34995 pregnancies. $N$ Engl J Med 1986; 315: 615-9.

${ }^{19}$ Bréart G. Un problème de décision en périnatalogie: l'enregistrement continu du coeur foetal pendant le travail. Rev Epidém et Santé Publ 1984; 32: 34-9.

${ }^{20}$ Committee to study the prevention of low birthweight. Preventing low birth weight. Washington: Institute of Medicine, National Academy Press, 1985.

${ }^{21}$ Hall MH, Chng PK, McGillivray I. Is routine antenatal care worthwhile? Lancet 1980; ii: 78-80.

22 National Institutes of Health consensus development conference. The use of diagnostic ultrasound imaging during pregnancy. JAMA 1984; 252: 669-72.

${ }^{23}$ Kaminski M, Bréart G, Buekens P, et al (eds). Perinatal care delivery systems, description and evaluation in European Community countries. Oxford: Oxford University Press, 1986.

${ }^{24}$ Enkin M, Chalmers I. Effectiveness and satisfaction in antenatal care. London: SIMP/Heinemann, 1982.

${ }^{25}$ Chard T, Richards M. Benefits and hazards of the new obstetrics. London: SIMP, 1977.

${ }^{26}$ Parboosingh J, Kerr M. Innovations in the role of obstetric hospitals in prenatal care. In: Effectiveness and satisfaction in antenatal care, Enkin M, Chalmers I (eds). London: SIMP/Heinemann, 1982: 254-65.

${ }^{27}$ Robinson S, Golden J, Bradley S. The role of the midwife in the provision of antenatal care. In: Effectiveness and satisfaction in antenatal care. Enkin M, Chalmers I (eds). London: SIMP/Heinemann, 1982: 23446.

${ }^{28}$ Hall M, Macintyre S, Porter M. Antenatal care assessed. Aberdeen: Aberdeen University Press, 1985. 